\title{
The First Korean Case of Griscelli Syndrome Type 2 With Hemophagocytic Lymphohistiocytosis and Partial Albinism
}

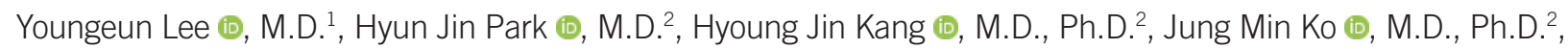

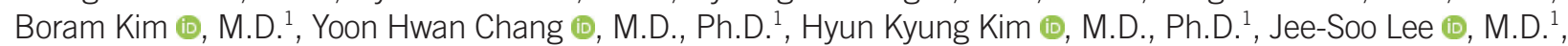

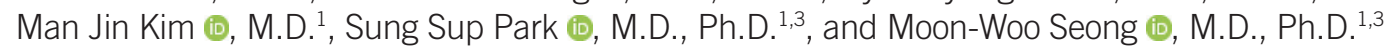

${ }^{1}$ Department of Laboratory Medicine, Seoul National University Hospital, Seoul National University College of Medicine, Seoul, Korea; ${ }^{2}$ Department of Pediatrics, Seoul National University Children's Hospital, Seoul National University College of Medicine, Seoul, Korea; ${ }^{3}$ Biomedical Research Institute, Seoul National University Hospital, Seoul, Korea

\section{Dear Editor,}

Hemophagocytic lymphohistiocytosis (HLH) is a systemic hyperinflammatory syndrome characterized by fever, hepatosplenomegaly, cytopenia, hypertriglyceridemia, and hypofibrinogenemia [1]. HLH can be divided into primary and secondary HLH. Primary HLH occurs mainly in children often as a result of genetic predisposition, whereas secondary HLH occurs mainly in adults and is commonly triggered by viral/bacterial infections or malignancy [2]. For patients with childhood-onset HLH, genetic testing is useful, as the accompanying symptoms depend on the genes involved. Griscelli syndrome (GS) was first reported in 1978 in a patient with partial albinism with immunodeficiency and is divided into three subtypes [3]. While partial albinism is a common finding in all three subtypes, $\mathrm{HLH}$ is notably characterized by GS type 2 (GS2), caused by a variant of RAB27A. We report the first case of a Korean patient with GS2. This study was approved by the Institutional Review Board of Seoul National University Hospital (SNUH), Seoul, Korea (approval number: 2107172-1236), and informed consent for genetic testing was obtained from the patient's parents.

A one-month-old boy was transferred to SNUH because of progressive cytopenia in April 2021. A complete blood count (CBC) revealed a $\mathrm{Hb}$ level of $77 \mathrm{~g} / \mathrm{L}$, absolute neutrophil count (ANC) of $2,545 \times 10^{6} / \mathrm{L}$, and platelet count of $81 \times 10^{9} / \mathrm{L}$. As a granulocyte colony-stimulating factor was used right before the transfer to our hospital, the ANC appeared to be normal. However, two days after the transfer, the ANC decreased to $1,065 \times$ $10^{6} / \mathrm{L}$. The patient was the first child, and his parents had no family history of hematologic disorders. There had been no perinatal problems during pregnancy, except fetal ascites, confirmed by ultrasound, at a gestational age of 37 weeks. After birth, fetal hydrops, including pleural effusion, subcutaneous edema, ascites, and systemic petechia were observed. CBC performed at that time revealed pancytopenia. Maternal screening test results for toxoplasmosis, rubella, cytomegalovirus, herpes simplex virus, and parvovirus performed right after childbirth were negative. Bacterial culture and viral infection tests of the patient were negative. Conservative treatments, including transfusion and granulocyte colony-stimulating factors, were administered, but cytopenia gradually progressed. On physical examination, the patient was found to have silvery-gray hair and hepatosplenomegaly. IgG, IgA, and IgM levels were normal. Hypofibrinogen-
Received: July 28, 2021

Revision received: August 10, 2021

Accepted: November 29, 2021

Corresponding author: Moon-Woo Seong, M.D., Ph.D.

Department of Laboratory Medicine, Seoul National University Hospital,

101 Daehak-ro, Jongno-gu, Seoul 03080, Korea

Tel: +82-2-2072-4180, Fax: +82-2-747-0359

E-mail: mwseong@snu.ac.kr

\section{(c) (1) (9)}

\section{(c) Korean Society for Laboratory Medicine}

This is an Open Access article distributed under the terms of the Creative Commons Attribution Non-Commercial License (https://creativecommons.org/licenses/by-nc/4.0) which permits unrestricted non-commercial use, distribution, and reproduction in any medium, provided the original work is properly cited. 

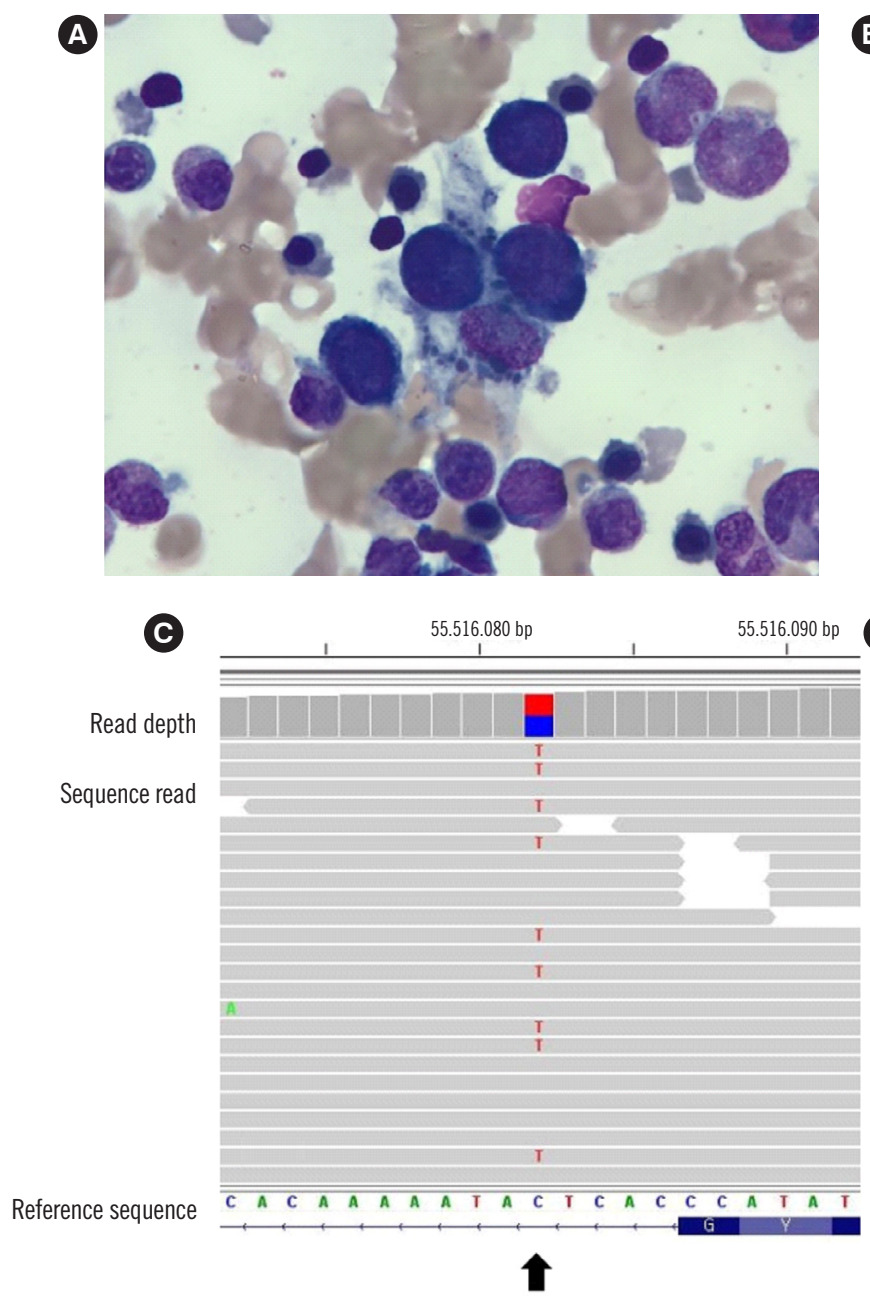

E

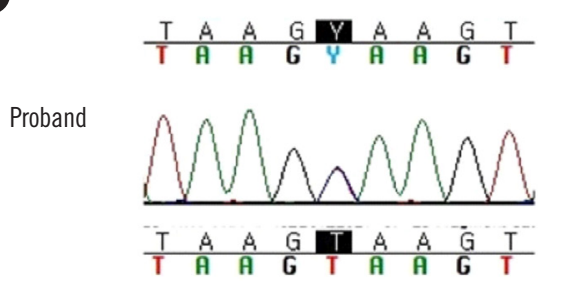

Father

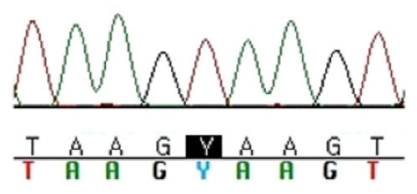

Mother

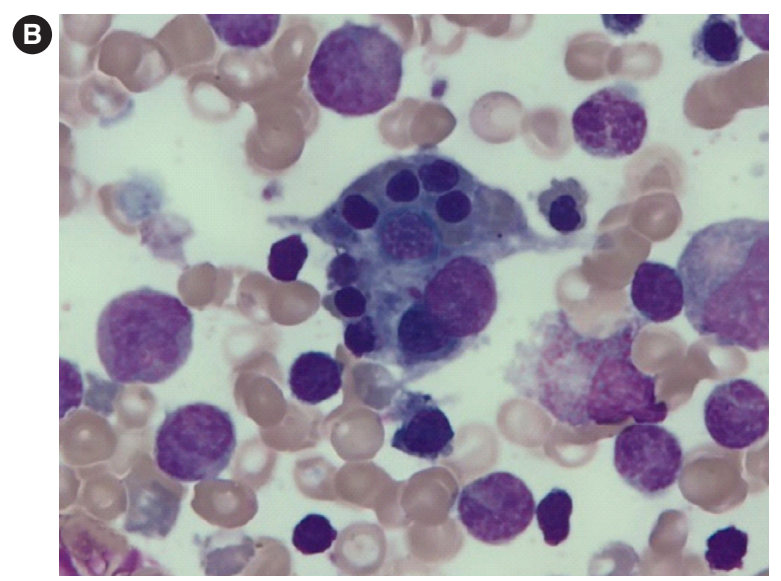

(D)

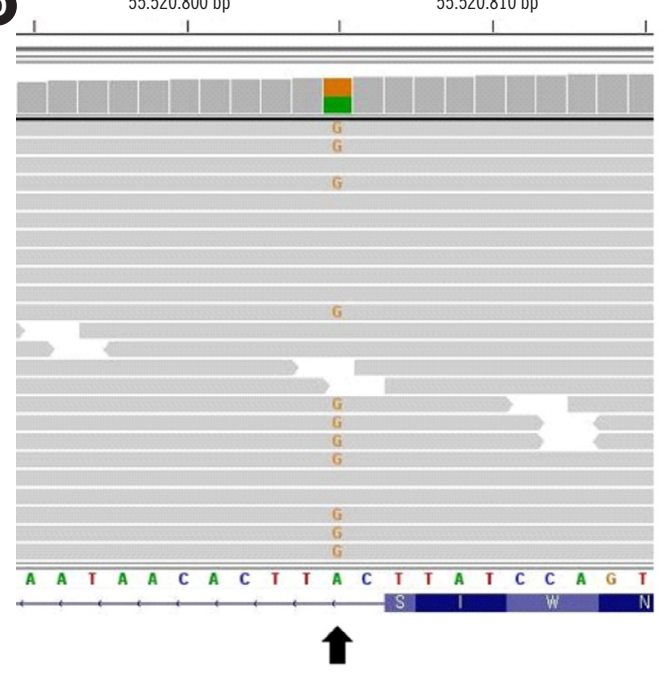

c. $467+5 G>A$
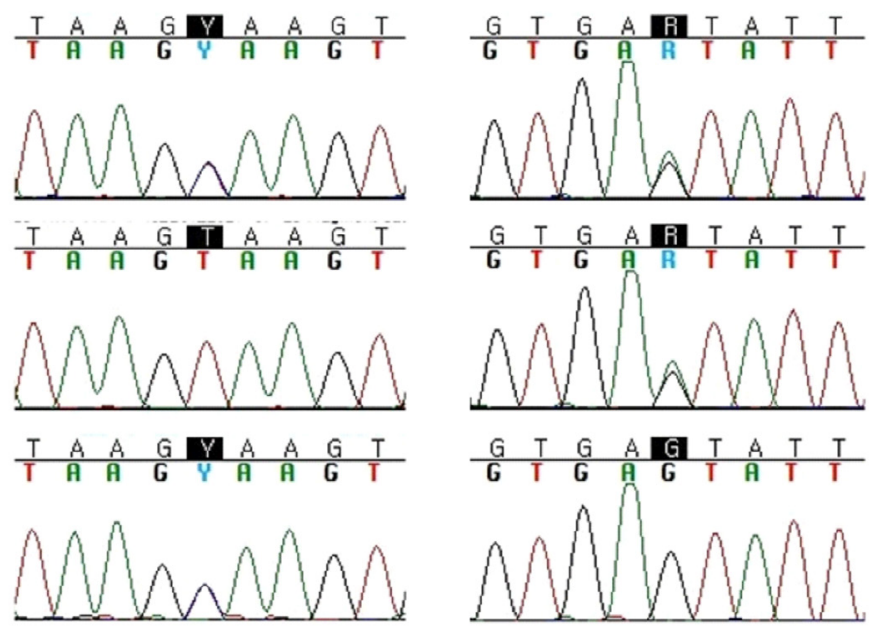

Fig. 1. Bone marrow morphologic characteristics of the patient, next-generation sequencing data visualization using Integrative Genomics Viewer, and Sanger sequencing results revealing two RAB27A variants. (A, B) Hemophagocytes with ingested granulocytes (A) and multiple ingested nucleated red blood cells and erythroid progenitors (B) on the bone marrow aspirate smears (Wright-Giemsa stain, $\times 1,000$ ). (C, D) Sequences of the RAB27A gene showing two splice site variants, c.467+5G >A (C) and c.343+2T >C (D). (E) Sanger sequencing chromatograms of the two RAB27A variants in the patient and his parents. 
emia (129 mg/dL; reference interval, 192-411 mg/dL), hyperferritinemia (3,557.41 mg/dL; reference interval, 21.8-274.7 $\mathrm{mg} / \mathrm{dL})$, and elevated IL-2 receptor level $(5,465 \mathrm{U} / \mathrm{mL}$; reference interval, 158-623 U/mL) were confirmed. Hemophagocytic histiocytes were observed on the bone marrow aspirate smear (Fig. $1 \mathrm{~A}, \mathrm{~B})$. The overall results were consistent with $\mathrm{HLH}$, according to the revised HLH-2004 diagnostic criteria [1]. The patient was started on dexamethasone and cyclosporine treatment. Simultaneously, we performed a gene panel testing, which revealed two splice site variants in RAB27A (Fig. 1C, D): NM_004580.4
(RAB27A):C.467+5G>A, with a variant allele frequency (VAF) of 49.81\%, and NM_004580.4(RAB27A):C.343+2T >C, with a VAF of $52.68 \%$.

We assessed both variants as likely pathogenic based on the 2015 American College of Medical Genetics and Genomics and the Association for Molecular Pathology guidelines [4]. These variants are absent from controls in large population databases, such as gnomAD (https://gnomad.broadinstitute.org/) and the Korean Reference Genome Database (http://coda.nih.go.kr/coda/ KRGDB/). The novel variant c.343+2T >C, located in the splice

Table 1. Genetic and clinical characteristics of patients with RAB27A variants

\begin{tabular}{|c|c|c|c|c|c|}
\hline Variant & Protein change & Inheritance & HLH & Partial albinism & Reference \\
\hline c. $467+5 G>A$ & Splice site & Homozygous & No & Yes & {$[5]$} \\
\hline c. $65 \mathrm{~A}>\mathrm{G}$ & Lys22Arg & Homozygous & Yes* & Yes & {$[6]$} \\
\hline $\begin{array}{l}\text { c. } 227 \mathrm{C}>\mathrm{T} \\
\mathrm{c.} .476 \mathrm{~A}>\mathrm{G}\end{array}$ & $\begin{array}{l}\text { Ala76Val } \\
\text { Tyr159Cys }\end{array}$ & Compound heterozygous & Yes & No & {$[7]$} \\
\hline $\begin{array}{l}\text { c. } 400 \_401 \text { delAA } \\
\text { c. } 74 T>G\end{array}$ & $\begin{array}{l}\text { Lys134Glufs*2 } \\
\text { Val25Gly }\end{array}$ & Compound heterozygous & Yes & No & [7] \\
\hline c. $428 \mathrm{~T}>\mathrm{C}$ & Val143Ala & Homozygous & Yes & No & {$[7]$} \\
\hline c.422-424delGAG & Arg141-Val142delinslle & Homozygous & Yes & No & {$[7]$} \\
\hline $\begin{array}{l}\text { c. } 422-424 \text { delGAG } \\
\text { c. } 487 \mathrm{~A}>\mathrm{C}\end{array}$ & $\begin{array}{l}\text { Arg141-Val142delinslle } \\
\text { Ser163Arg }\end{array}$ & Compound heterozygous & Yes & No & {$[7]$} \\
\hline $\begin{array}{l}\text { c.422-424delGAG } \\
\text { c.514-518deICAAGC }\end{array}$ & $\begin{array}{l}\text { Arg141-Val142delinslle } \\
\text { Gln172Asnfs*2 }\end{array}$ & Compound heterozygous & Yes & No & [7] \\
\hline 5' UTR dup/inv & Structural variant & Homozygous & Yes & No & [7] \\
\hline $\begin{array}{l}\text { 5' UTR dup/inv/del } \\
\text { c. } 559 \mathrm{C}>\mathrm{T}\end{array}$ & $\begin{array}{l}\text { Structural variant } \\
\text { Arg187Trp }\end{array}$ & Compound heterozygous & Yes & No & [7] \\
\hline $\begin{array}{l}\text { 5' UTR dup/inv/del } \\
\text { c. } 239 \mathrm{G}>\mathrm{C}\end{array}$ & $\begin{array}{l}\text { Structural variant } \\
\text { Arg80Thr }\end{array}$ & Compound heterozygous & Yes & No & {$[7]$} \\
\hline $\begin{array}{l}\text { 5' UTR dup/inv } \\
\text { c. } 550 \mathrm{C}>\mathrm{T}\end{array}$ & $\begin{array}{l}\text { Structural variant } \\
\text { Arg184* }\end{array}$ & Compound heterozygous & Yes & № & {$[7]$} \\
\hline c.53_54delCT & Ser18Trpfs*15 & Homozygous & $\mathrm{No}^{\dagger}$ & Yes & {$[9]$} \\
\hline c. $131 T>C$ & Ile44Thr & Homozygous & Yes & Yes & {$[9]$} \\
\hline c.149delG & Arg50Lysfs*35 & Homozygous & Yes & Yes & {$[9]$} \\
\hline $\begin{array}{l}\text { c. } 239 \mathrm{G}>\mathrm{C} \\
\text { c. } 550 \mathrm{C}>\mathrm{T}\end{array}$ & $\begin{array}{l}\text { Arg80Thr } \\
\text { Arg184* }\end{array}$ & Compound heterozygous & Yes & Yes & {$[9]$} \\
\hline c. $240-2 A>C$ & Splice site & Homozygous & Yes & Yes & {$[9]$} \\
\hline $\begin{array}{l}\text { c. } 352 C>T \\
\text { c. } 467+1 G>C\end{array}$ & $\begin{array}{l}\text { Gln118* } \\
\text { Splice site }\end{array}$ & Compound heterozygous & Yes & Yes & {$[9]$} \\
\hline c. $550 \mathrm{C}>\mathrm{T}$ & $\operatorname{Arg} 184^{*}$ & Homozygous & Yes & Yes & [9] \\
\hline c. $244 C>T$ & Arg82Cys & Homozygous & Yes & $\Delta^{\ddagger}$ & {$[10]$} \\
\hline $\begin{array}{l}\text { c. } 343+2 T>C \\
\text { c. } 467+5 G>A\end{array}$ & Splice site & Compound heterozygous & Yes & Yes & This study \\
\hline
\end{tabular}

${ }^{*}$ Hemophagocytosis was identified by liver biopsy; ${ }^{\dagger}$ The patient presented with cytopenia and immunological abnormalities but showed no evidence of hemophagocytosis in bone marrow biopsy; `Phenotypic heterogeneity was observed in multiple families with the same homozygous missense variant from asymptomatic cases to the typical clinical presentation of GS2.

Abbreviations: HLH, hemophagocytic lymphohistiocytosis; GS2, Griscelli syndrome type 2. 
donor site, was predicted to interfere with mRNA splicing by a splicing prediction algorithm. We applied PM2 and PVS1 as evidence of pathogenicity. The other variant, c. $467+5 G>A$, resulted in the skipping of exon 5 in a previous study [5]. Thus, we assessed this variant as likely pathogenic based on PM2, PS3, and PP5. Heterozygosity was confirmed by Sanger sequencing DNA samples from the parents (Fig. 1E). No variants were found in other HLH or pigmentary disorder-associated genes in the panel, including PRF1, UNC13D, STX11, STXBP2, LYST, and AP3B1. The patient's $C B C$ profile steadily improved, and he has been in good condition for more than seven months now. The patient is undergoing regular follow-up, and a stem cell transplantation is planned in a few months.

RAB27A is a member of the small GTPase family and is expressed in various cells, including melanocytes and lymphocytes [6]. Specific changes caused by an RAB27A variant lead to inhibition of the melanosome transport process and eventually cause pigmentary dilution, a characteristic of GS2 [7-9]. RAB27A is also involved in cytotoxic granule exocytosis through binding with specific effectors, leading to immune impairment and predisposition to HLH [8]. However, not all patients with the RAB27A variant develop both symptoms. Specific RAB27A variant selectively impairs only the RAB27A-MUNC13-4 interaction and does not affect the RAB27A-MLPH/SLAC2-A interaction, leading to immune abnormalities but normal pigmentation [7]. The effects on leukocytes and melanocytes vary depending on the transcription start sites, resulting in normal pigmentation in some cases (Table 1) [7]. Even with the same homozygous missense variant, phenotypic variability has been reported [10].

We present a GS2 case with RAB27A splice site variants. One novel variant, c.343+2T $>C$, and one reported variant, c. $467+5 G>A$, were identified. The previously reported case presented with neurological symptoms, graying hair, and no signs of immunodeficiency. These results are closely related to GS type 1 rather than GS2 [5]. However, an RAB27A homozygous variant, c.467+5G $>A$, was confirmed by Sanger sequencing and was predicted to result in a premature termination codon (p.Ser115Lysfs $\left.{ }^{*} 15\right)$. In this case, the patient had silvery-gray hair and was diagnosed as having $\mathrm{HLH}$, consistent with the classic GS2 phenotype. These phenotypic differences can be attributed to the location of the transcription start site. However, the underlying mechanism was not confirmed in the present study.

GS2 is an inherited disorder that induces immune impairment and oculocutaneous albinism. However, some patients have only immunodeficiency, without hypopigmentation. To allow appropriate management, genetic testing should be performed even in patients with $\mathrm{HLH}$ without hypopigmentation, and RAB27A should be included in the gene panel for $\mathrm{HLH}$ or albinism evaluation.

\section{ACKNOWLEDGEMENTS}

None.

\section{AUTHOR CONTRIBUTIONS}

Seong MW and Lee $\mathrm{Y}$ designed the study and wrote the manuscript. Kang HJ, Ko JM, Chang YH, and Kim HK reviewed the medical records of the patient. Park HJ, Kim B, and Lee JS collected and interpreted the data. Kim MJ, Park SS, and Seong MW contributed to the revision of the manuscript. All authors approved the final manuscript to be published.

\section{CONFLICTS OF INTEREST}

None declared.

\section{RESEARCH FUNDING}

None declared.

\section{ORCID}

Youngeun Lee

Hyun Jin Park

Hyoung Jin Kang

Jung Min Ko

Boram Kim

Yoon Hwan Chang

Hyun Kyung Kim

Jee-Soo Lee

Man Jin Kim

Sung Sup Park

Moon-Woo Seong

https://orcid.org/0000-0002-4439-2283 https://orcid.org/0000-0001-7062-0414 https://orcid.org/0000-0003-1009-6002 https://orcid.org/0000-0002-0407-7828 https://orcid.org/0000-0001-5695-8902 https://orcid.org/0000-0002-9010-5281 https://orcid.org/0000-0003-2401-3933 https://orcid.org/0000-0002-7005-5686 https://orcid.org/0000-0002-9345-6976 https://orcid.org/0000-0003-3754-4848 https://orcid.org/0000-0003-2954-3677

\section{REFERENCES}

1. Henter JI, Horne A, Aricó M, Egeler RM, Filipovich AH, Imashuku S, et al. HLH-2004: Diagnostic and therapeutic guidelines for hemophagocytic lymphohistiocytosis. Pediatr Blood Cancer 2007;48:124-31.

2. Janka G, Imashuku S, Elinder G, Schneider M, Henter JI. Infection- and malignancy-associated hemophagocytic syndromes: secondary hemophagocytic lymphohistiocytosis. Hematol Oncol Clin North Am 1998; 12:435-44. 
3. Griscelli C, Durandy A, Guy-Grand D, Daguillard F, Herzog C, Prunieras M. A syndrome associating partial albinism and immunodeficiency. Am J Med 1978;65:691-702.

4. Richards S, Aziz N, Bale S, Bick D, Das S, Gastier-Foster J, et al. Standards and guidelines for the interpretation of sequence variants: a joint consensus recommendation of the American College of Medical Genetics and Genomics and the Association for Molecular Pathology. Genet Med 2015;17:405-24.

5. Lee JYW, Eldeeb MS, Hsu CK, Saito R, Abouzeid SA, McGrath JA. Further evidence for genotype-phenotype disparity in Griscelli syndrome. Br J Dermatol 2017;176:1086-9.

6. Ohbayashi N, Mamishi S, Ishibashi K, Maruta Y, Pourakbari B, Tamizifar $\mathrm{B}$, et al. Functional characterization of two RAB27A missense mutations found in Griscelli syndrome type 2. Pigment Cell Melanoma Res
2010;23:365-74.

7. Ohishi Y, Ammann S, Ziaee V, Strege K, Groß M, Amos CV, et al. Griscelli syndrome type 2 sine albinism: unraveling differential RAB27A effector engagement. Front Immunol 2020;11:612977.

8. Fukuda M. Rab27 effectors, pleiotropic regulators in secretory pathways. Traffic 2013;14:949-63.

9. Meeths M, Bryceson YT, Rudd E, Zheng C, Wood SM, Ramme K, et al. Clinical presentation of Griscelli syndrome type 2 and spectrum of $R A$ B27A mutations. Pediatr Blood Cancer. 2010;54:563-72.

10. Al-Sulaiman R, Othman A, El-Akouri K, Fareed S, AlMulla H, Sukik A, et al. A founder RAB27A variant causes Griscelli syndrome type 2 with phenotypic heterogeneity in Qatari families. Am J Med Genet A 2020;182:2570-80. 